\title{
Avaliação das condições de trafegabilidade e impactos ambientais de uma estrada não pavimentada situada no sudoeste de Minas Gerais, Brasil
}

Assessment of traffic conditions and environmental impact of an unpaved road located in southwest

Minas Gerais, Brazil

Evaluación de las condiciones del tráfico y los impactos ambientales de una carretera sin pavimentar ubicada en el suroeste de Minas Gerais, Brasil

Letícia Bueno de Oliveira Rocha ORCID: https://orcid.org/0000-0002-6838-136X Universidade do Estado de Minas Gerais, Brasil E-mail: leticiaborocha@gmail.com

Rômulo Amaral Faustino Magri ORCID: https://orcid.org/0000-0002-9510-3330 Universidade do Estado de Minas Gerais, Brasil E-mail: romulo.magri@uemg.br

Tereza Cristina de Faria Kraüss Pereira ORCID: https://orcid.org/0000-0003-2077-0881 Universidade do Estado de Minas Gerais, Brasil E-mail: terezackrauss@gmail.com

\begin{abstract}
Resumo
Grande parte da malha viária do Brasil é estruturada por estradas não pavimentadas. As estradas são elementos da paisagem de suma importância para a economia das cidades e da sociedade que as margeiam. A rodovia não pavimentada em estudo possui aproximadamente $25 \mathrm{~km}$ de extensão sendo elo entre a cidade de São João Batista do Glória/MG e o distrito de Ponte Alta, munícipio de Delfinópolis/MG. O presente estudo visou analisar as características do meio físico, identificar os impactos ambientais e problemas de trafegabilidade e apresentar alternativas de conservação e manutenção da via. Para esse estudo levantou-se dados primários e secundários de características do meio físico por meio da utilização de técnicas de fotointerpretação, vetorização e geoprocessamento. Foram realizadas visitas in loco com vistas nas condições de trafegabilidade inclusive a identificação de possíveis impactos ambientais. Os sistemas de drenagem pluvial envolvendo o abaulamento transversal com canaletas laterais e bacias de contenção (barraginhas), além de auxiliarem na conservação da estrada, acumulam água pluvial e partículas de solo, promovendo a mitigação de assoreamento de cursos hídricos. Os resultados dessa pesquisa são importantes para auxiliar a gestão administrativa dos munícipios de São João Batista do Glória-MG e Delfinópolis-MG na adoção de práticas conservacionistas aplicáveis a manutenção e conservação das estradas não pavimentadas, com vistas ao aprimoramento das técnicas de manutenção referente a trafegabilidade e ao gerenciamento ambiental.

Palavras-chave: Sistema de drenagem pluvial; Estradas rurais; Assoreamento de cursos hídricos; Conservação de estradas rurais.

Abstract

Much of Brazil's road network is structured by unpaved roads. Roads are elements of the landscape of paramount importance for the economy of cities and the society that surround them. The unpaved highway under study is approximately $25 \mathrm{~km}$ long and is a link between the city of São João Batista do Glória / MG and the district of Ponte Alta, municipality of Delfinópolis / MG. The present study aimed to analyze the characteristics of the physical environment, identify the environmental impacts and trafficability problems and present alternatives for road conservation and maintenance. For this study, primary and secondary data of physical characteristics were collected through the use of photointerpretation, vectorization and geoprocessing techniques. On-site visits were carried out with a view to the traffic conditions including the identification of possible environmental impacts. The rain drainage systems involving the transverse bulging with lateral channels and containment basins (barraginhas), in addition to helping in the conservation of the road, accumulate rainwater and soil particles, promoting the mitigation of silting of water courses. The results of this research are important to assist the administrative management of the municipalities of São João Batista do Glória-MG and Delfinópolis-MG in the adoption of conservationist practices applicable to the maintenance and conservation of unpaved roads, with a view to improving the maintenance techniques related to trafficability and environmental management.
\end{abstract}


Keywords: Rain drainage system; Rural road; Silting up of water courses; Conservation of rural roads.

\section{Resumen}

Gran parte de la red vial de Brasil está estructurada por caminos sin pavimentar. Las carreteras son elementos del paisaje de suma importancia para la economía de las ciudades y la sociedad que las rodea. La carretera sin pavimentar en estudio tiene una longitud aproximada de $25 \mathrm{~km}$, siendo un enlace entre la ciudad de São João Batista do Glória / MG y el distrito de Ponte Alta, municipio de Delfinópolis / MG. Para este estudio, se recolectaron datos primarios y secundarios sobre características físicas mediante el uso de técnicas de fotointerpretación, vectorización y geoprocesamiento. Se realizaron visitas in situ teniendo en cuenta las condiciones del tráfico, incluida la identificación de posibles impactos ambientales. Los sistemas de drenaje pluvial que involucran el abombamiento transversal con canales laterales y cuencas de contención (barraginhas), además de ayudar en la conservación de la vía, acumulan agua de lluvia y partículas de suelo, promoviendo la mitigación de la sedimentación de los cursos de agua. Los resultados de esta investigación son importantes para ayudar a la gestión administrativa de los municipios de São João Batista do GlóriaMG y Delfinópolis-MG en la adopción de prácticas conservacionistas aplicables al mantenimiento y conservación de caminos sin pavimentar, con miras a mejorar el mantenimiento. técnicas relacionadas con la transitabilidad y la gestión ambiental.

Palabras clave: Sistema de drenaje lluvia; Camino rural; Sedimentación de cursos de agua; Conservación de caminos rurales.

\section{Introduçãa}

A distribuição entre estradas pavimentadas e não pavimentadas no Brasil é desproporcional e desigual. Segundo o Boletim Estatístico emitido pela Confederação Nacional do Transporte [CNT] em de fevereiro de 2020, a malha rodoviária total do Brasil corresponde a $1.562 .682 \mathrm{~km}$. Desse total, $1.349 .474 \mathrm{~km}$ são de vias não pavimentadas, ou seja, apenas 13,64\% das estradas brasileiras são pavimentadas, o que equivale a $213.208 \mathrm{~km}$ (CNT, 2020).

As estradas não pavimentadas são elementos que estruturam a rede de paisagem viária e são de suma importância para o desenvolvimento econômico e social do país. Por meio dessas estruturas que se consolida o escoamento de produtos agrícolas, que subsidia a economia do país e consequentemente proporciona a alimentação da população brasileira e matérias primas de diversas indústrias alimentícias. Além disso, a maioria das estradas não pavimentadas são elos entre cidades, vilas, distritos. Assim, são os meios de condução da comunidade rural aos centros urbanos, proporcionando acesso a hospitais, escolas, etc., alcançando assim um direito social assegurado pelo Estado para população (Martins, Campos, \& Nascimento, 2019).

A construção das estradas não pavimentadas pelo evidente fato de eliminar a cobertura vegetal e impermeabilizar o solo pela sua compactação, ocasiona um fator predisponente à erosão. Ao impermeabilizar o leito carroçável com a compactação gera o acúmulo das águas nas margens da estrada, direcionando-as a favor da alta declividade do terreno (Bertolini, Drugowich, Lombardi Neto, \& Bellinazzi Junior, 1994).

A má gestão do governo com recursos financeiros aplicados para manutenção de estradas não pavimentadas, segundo Cunha, Cruz e Santos (2014) faz com que a atividade de gerenciamento das estradas seja realizada sem planejamento, procedendo de formas improvisadas como a implantação de dispositivos dissipadores de energia e de drenagem pluvial (bacias de contenção, valas laterais, sarjetas, lombadas, técnica de proteção vegetal, entre outros) sem o dimensionamento e locais de instalação correto.

Há um descaso com a conservação dessas vias o que acarreta indiretamente em graves problemas ambientais como: perdas de solos e consequentemente o assoreamento de cursos d'água, devido ao surgimento de processos erosivos (Mortoni, Gonçalves, \& Nascimento, 2020).

O gerenciamento ambiental e de trafegabilidade das estradas não pavimentadas se efetiva pela redução dos problemas de erosão, aplicando medidas de controle e conservação como a construção de dispositivos de drenagem pluvial (Casarin \& Oliveira, 2009).

Cunha, Thomaz, e Vestena (2012) ressaltam a importância das estradas para locomoção e frisam a necessidade de pesquisas mais específicas voltadas para planejamento do seu uso (trafegabilidade) e de seus impactos nos cursos hídricos.

Para que os diversos problemas encontrados nessas vias sejam prevenidos e/ou amenizados é fundamental a realização 
de manutenção periódica bem como o acompanhamento do estado de conservação dessas vias (Cunha et al., 2014).

Essa pesquisa se desenvolveu no âmbito dos munícipios de São João Batista do Glória e Delfinópolis-MG. A malha viária total desses municípios é composta por 1451,80 km de estradas, desse total 98,33\% são de estradas não pavimentadas (Santos, Oliveira, Biazotti Collares, Pereira, \& Collares, 2013).

Na região atendida pela estrada não pavimentada há um grande potencial turístico, uma vez que se localiza no âmbito da área de influência da Serra da Canastra (Fonseca, 2012). Nesse sentido, as estradas, dentre todas as obras de infraestrutura necessárias ao desenvolvimento do turismo, cumprem papel fundamental e muitas vezes se apresentam como um diferencial na escolha e fidelização do destino turístico.

Diante desse cenário, constata-se que as estradas não pavimentadas predominam na paisagem dos munícipios de estudo e carecem de pesquisas sobre os impactos positivos e negativos que geram no meio ambiente e técnicas de manutenção e conservação, assegurando o gerenciamento ambiental e trafegabilidade desses elementos.

O desenvolvimento sustentável de uma região perpassa por estudo em estradas não pavimentadas, e envolve a administração pública, a população rural e turística, que necessitam de um sistema viário para suprir as diversas necessidades demandadas por essa região (Casarin, 2008).

O objetivo geral desse estudo foi contribuir para o gerenciamento de estradas não pavimentadas, avaliando e apresentando alternativas para a sua funcionalidade, prevenção e controle ambiental na sua abrangência. Esse estudo tem o propósito de auxiliar no desenvolvimento de uma região, reconhecendo a relevância das estradas não pavimentadas como utilidade pública. Os objetivos específicos foram analisar as características do meio físico; identificar os impactos ambientais e problemas de trafegabilidade; e apresentar alternativas de conservação e manutenção da via. Com esses três propósitos realizados espera-se atender a um processo de gestão que envolve a comunicação por via terrestre, os cursos d'água da região e o desenvolvimento socioeconômico.

\section{Metodologia}

\subsection{Caracterização da área de estudo}

Essa pesquisa se desenvolveu no âmbito dos munícipios de São João Batista do Glória e Delfinópolis-MG, situados na mesorregião Sul e Sudeste do estado de Minas Gerais, precisamente em um trecho de $25 \mathrm{~km}$ de uma rodovia não pavimentada, intitulada de BR-464, que faz elo entre a área urbana de São João Batista do Glória-MG e ao distrito de Ponte Alta no munícipio de Delfinópolis-MG (Figura 1).

O turismo é uma atividade frequente na região de estudo. Às margens dos municípios de São João Batista do Glória e Delfinópolis-MG localiza-se o Rio Grande próximo à Usina Hidrelétrica de Furnas. O município de Delfinópolis e São João Batista do Glória - MG fazem parte do circuito turístico da Serra da Canastra. Esses munícipios possuem grande número de cachoeiras, o que os tornam conhecidos regionalmente por "cidades das cachoeiras". 
Figura 1 - Localização da área de estudo.

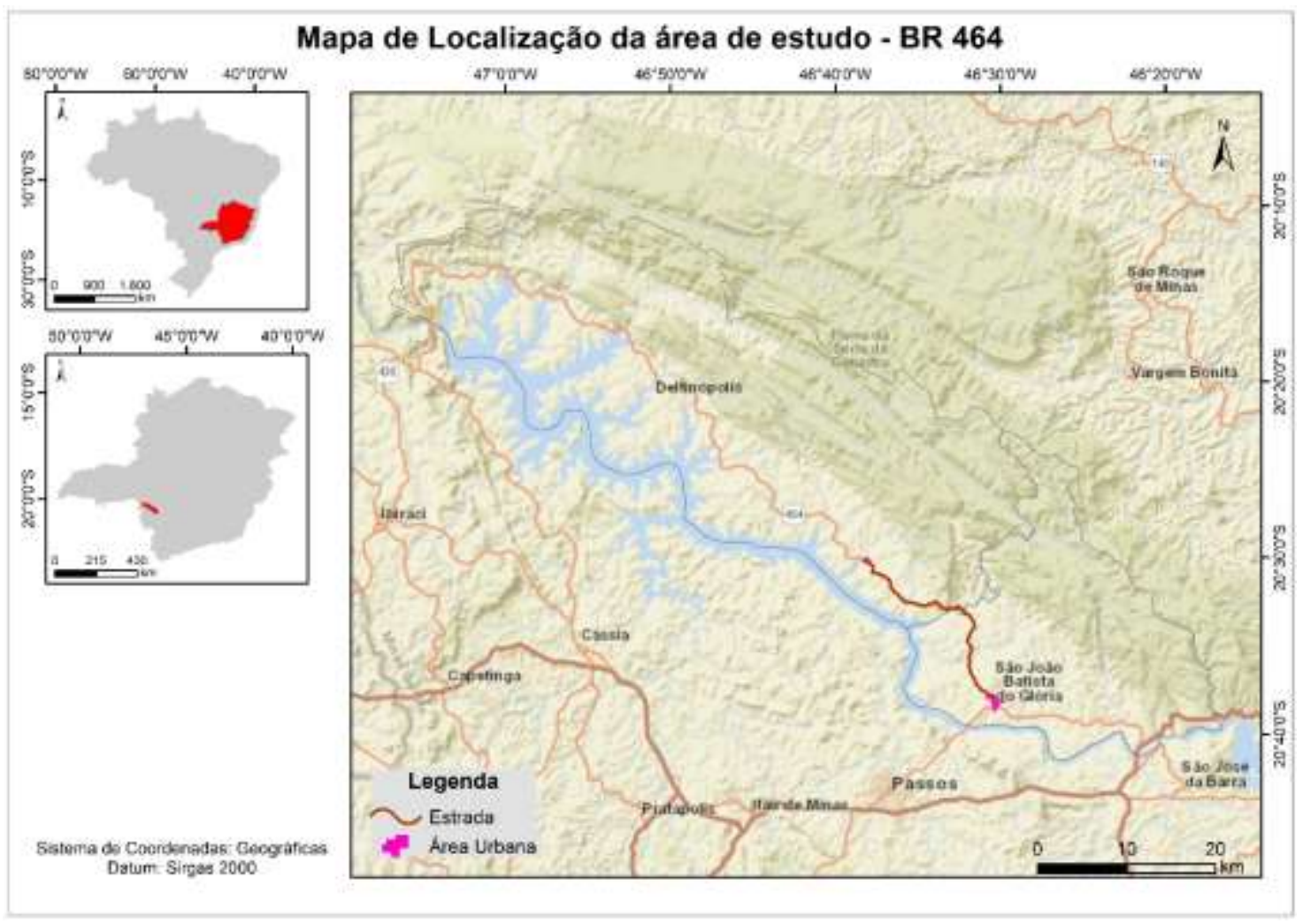

Fonte: Autores (2021).

\subsubsection{Caracterização do Munícipio de São João Batista do Glória}

Segundo o Instituto Brasileiro de Geografia e Estatística [IBGE] (2010), a população total de São João Batista do Glória/MG é de 6.887 habitantes, desse total 1.280 habitantes estão localizados na zona rural. Possui uma área total de 547,9 $\mathrm{km}^{2}$ e o Índice de Desenvolvimento Humano Municipal [IDHM] é de 0,724.

O clima local de São João Batista do Glória-MG é o tropical de altitude e a temperatura registrada varia entre a média máxima de $28,5^{\circ}$ e a média mínima de $14,6^{\circ}$, tendo uma média anual de $20,7^{\circ} \mathrm{C}$. Entretanto, são registradas temperaturas acima $\operatorname{dos} 30^{\circ} \mathrm{C}$, bem como próximas a zero, ou mesmo negativas, nos períodos de maior intensidade de calor e frio, respectivamente. O período de chuvas do município tem característica da região Sul Sudeste com altos índices pluviométricos frequentes entre os meses de outubro a março (Godinho, Soares, Bertipaglia, Carvalho, \& Dian, 2012). O índice médio pluviométrico anual do município é de 1.426,3 mm (IBGE, 2010).

\subsubsection{Caracterização do Munícipio de Delfinópolis}

De acordo com a Sinopse do Censo Demográfico 2010, Delfinópolis possui população total de 6.830 habitantes, desse total 1.984 habitantes estão localizados na zona rural. Possui uma área territorial total de $1.378,4 \mathrm{~km}^{2} \mathrm{e}$ o IDHM igual a 0,740 com economia embasada no setor agrícola, com cultivo de cana-de-açúcar, soja e banana (IBGE, 2010). Há presença de atividades do setor minerário com mineradoras de quartzito na região (Almeida, 2014).

$\mathrm{O}$ clima é caracterizado por verão chuvoso e inverno seco. A temperatura média anual varia entre $22-23^{\circ} \mathrm{C}$, e precipitação média anual apresenta valores entre 1.200 e $1.800 \mathrm{~mm}$, concentrados principalmente na estação da primavera e verão (outubro a março) (Instituto Brasileiro de Meio Ambiente e dos Recursos Naturais Renováveis [IBAMA], 2005).

Além da agricultura e das atividades minerárias, outro setor que contribui vigorosamente com a economia é o turismo, 
pois a região apresenta grandes belezas cênicas. As principais atrações turísticas do município são cachoeiras e trilhas, sendo também o local de prática do turismo de aventura como: ciclismo, motociclismo, treaking, rappel, off-road e outros (Andrade, Carvalho, Godinho, \& Magri, 2016).

\subsection{Etapas da pesquisa}

A metodologia utilizada foi de caráter quantitativo-qualitativo para avaliação dos resultados (Pereira, Shitsuka, Parreira, \& Shitsuka, 2018).

Foram efetuadas avaliações considerando-se a área ao longo da estrada, para identificar os aspectos que influenciam os processos de degradação da mesma.

As etapas abordadas na pesquisa foram: Identificação dos impactos ambientais e os pontos críticos com processo de degradação existentes na área de entorno ou local; conhecimento das causas do processo de degradação da área; avaliação e estabelecimento de alternativas de melhorias destinadas às condições de tráfego, ao monitoramento e à manutenção da estrada.

\subsubsection{Identificação dos impactos ambientais e os pontos críticos com processo de degradação existentes na área de entorno ou local}

A identificação dos impactos ambientais e os pontos críticos com processo de degradação teve como limite o percurso de $25 \mathrm{~km}$ da estrada que permitiu identificar os aspectos do meio físico ao longo da estrada. Nesta etapa foram realizados os seguintes trabalhos: levantamento de dados existentes, fotointerpretação e vetorização, levantamento de campo, elaboração de produtos cartográficos e amostragem dos tipos de solo.

\subsubsection{Levantamento dos dados preexistentes}

Envolveu o levantamento de informações que deu suporte as atividades de campo e subsidiaram as análises e produtos finais, seguindo o roteiro:

- Indagações informais realizadas via telefone e/ou meio eletrônico (troca de e-mails) com o responsável pelo departamento de infraestrutura da prefeitura municipal do munícipio do São João Batista do Glória/MG a fim de obter informações informais relativas à área de abrangência da pesquisa (como realizam a manutenção da estrada não pavimentada, equipamentos utilizados, programas de gestão, etc.);

- Levantamento de dados cartográficos existentes: Mapas temáticos elaborados pela equipe do Projeto Grande Minas que realizou o Zoneamento Ambiental das Sub-Bacias Hidrográficas dos Afluentes Mineiro do Médio Rio Grande na escala de 1:50.000.

- Mapa de Macrounidades e Unidades Ambientais (Collares, Gomes, \& Santos, 2013);

- Mapa de drenagem (Biazotti Collares, Gomes, Silva, Pereira, \& Collares, 2013

- Mapa de uso e ocupação do solo (Dias, Vilela, Santos, Collares, \& Pejon, 2013);

- Mapa Geológico (Collares \& Gomes, 2013);

- Mapa de Declividade (Magri, Collares, \& Pejon, 2013);

- Mapa Hipsometrico (Magri et al., 2013);

- Mapa de Estrutura Viária (Santos et al., 2013).

- Elaboração de três quadros síntese, envolvendo os tipos de degradação e observações encontradas nos pontos críticos, impactos ambientais e propostas de alternativas de melhorias nas condições de conservação e manutenção da estrada. 


\subsubsection{Fotointerpretação e vetorização}

Essa etapa referiu-se à fotointerpretação de imagens de satélite disponíveis no hipermapa do aplicativo público Google ${ }^{\mathrm{TM}}$ Earth Pro.

Foi utilizado na identificação da estrada, objeto de estudo, como também na localização das atividades modificadoras do meio ambiente, cursos d’água e remanescentes florestais existentes na área. $\mathrm{O}$ auxílio das imagens foi importante também para comprovação da relevância de ocorrências a serem evidenciadas in loco.

\subsubsection{Levantamento de Campo}

Foram percorridos os $25 \mathrm{~km}$ da estrada não pavimentada, o trabalho de campo foi realizado nos horários 06h00mim até 18h00min. No levantamento de campo foram realizadas as seguintes atividades: diagnóstico da estrada referente à trafegabilidade e/ou sua conservação, localização dos pontos críticos através das coordenadas geográficas com auxílio do GPS de navegação GPSMAP ${ }^{\circledR} 76$ S GARMIN $®$ e fotografias com auxílio de uma câmera fotográfica Canon® Power Shot A2300. Os dados deram subsídios às próximas abordagens: Conhecimento das causas do processo de degradação da área; avaliação e propostas de alternativas de melhorias destinadas às condições de tráfego.

\subsubsection{Elaboração dos produtos cartográficos}

Os planos de informação do meio físico utilizados nesse trabalho foram disponibilizados pelo Projeto Grande Minas que realizou o Zoneamento Ambienta dos Afluentes Mineiro do Médio Rio Grande, na escala de 1:50.000. O software utilizado para o processamento dos planos de informação foi o Arc GIS® 10.5.1 da ESRI.

Como o Zoneamento Ambiental da Bacia Hidrográfica do Médio Rio Grande (GD7) envolveu produtos cartográficos para a área de toda unidade de planejamento, foi necessária realizar o recorte dos planos de informação para abranger somente a área dos munícipios em estudo. Os planos de informação temáticos utilizados foram: geológico; declividade; uso e ocupação do solo; hipsometrico; rede de drenagem; e bacias hidrográficas (macrounidades e unidades ambientais).

O procedimento para a adaptação dos planos de informação foi realizado utilizando os seguintes comandos do software Arc GIS® 10.5.1: Geoprocessing - Clip (para arquivos com formato vetoriais - shape) e ArcToolbox - Espatial Analyst Tools Extraction - Extract by mask (para arquivos em formato matricial - raster). Para realizar o detalhe dos mapas do meio físico de cada ponto crítico, foi utilizada a ferramenta de zoom disponível no software, dada pelo comando Geoprocessing - Buffer, com distância de 100 metros da estrada de estudo. Logo após, foi elaborado um banco de dados exclusivo dos munícipios em estudo, contendo dados espacializadas do meio físico como: declividade, hipsometria, uso e ocupação e geologia.

\subsubsection{Amostragem dos tipos de solos}

$\mathrm{Na}$ etapa de levantamento de campo foram realizadas coletas de amostras de solo em 07 (sete) pontos distintos e aleatórios na estrada de estudo. Foi realizado nas sete amostras de solo o ensaio de granulometria conjunta no Laboratório de Geologia e Geotecnia da UEMG/Passos. As amostras foram coletadas em uma distância de aproximadamente $5 \mathrm{em} 5 \mathrm{~km}$ de um ponto a outro, considerando o fato de ser uma rodovia não pavimentada, a fundamentação das coletas de solo se sustenta na caracterização do material de revestimento do leito estradal, podendo ser de material de empréstimo ou natural do próprio terreno.

O ensaio de Análise Granulométrica Conjunta foi realizado com base na NBR 7.181 da Associação Brasileira de Normas Técnicas [ABNT] (2016). Este ensaio teve por objetivo determinar o tamanho das partículas e seu percentual de ocorrência, o que corresponde ao diâmetro e a percentagem dos grãos de solo que passam nas peneiras. A partir destes dados é traçada a curva granulométrica, que possibilitará a determinação das frações das partículas do solo.

Com a amostra previamente preparada e após o período de repouso (24 horas), estas foram transferidas para o conjunto 
dispersor juntamente com água destilada.

Na sequência, os materiais foram transferidos para uma proveta graduada e iniciou-se a leitura na suspensão, utilizando um densímetro e mediu-se a temperatura, com auxílio de um termômetro. As leituras foram realizadas seguindo um tempo prédeterminado, sendo $1 ; 2 ; 4 ; 8 ; 15 ; 30 ; 60 ; 120 ; 240$ e 480 minutos.

Após a etapa supracitada, o material foi lavado na peneira $\mathrm{n}^{\circ} 200$ e secado na estufa, para posteriormente realizar o peneiramento fino. Todos os valores obtidos foram anotados nas planilhas de ensaio, os valores da percentagem retida foram calculados e obteve-se a curva granulométrica.

\subsubsection{Determinação das causas do processo de degradação da área}

Nesta etapa foram avaliadas as caraterísticas do meio físico que influenciam na degradação da estrada, visando a sua conservação. Foi considerada a área inserida numa faixa, que permita identificar os aspectos do meio físico e os dispositivos de drenagem pluvial ao longo da estrada.

\subsubsection{Avaliação e propostas de alternativas de melhorias destinadas às condições de tráfego}

Nesta etapa foi elaborada uma avaliação da existência da medida de controle envolvendo as características do local de sua instalação.

As informações básicas para apresentação das alternativas para melhorias das condições de tráfego, monitoramento e manutenção da estrada foram sintetizadas em um terceiro quadro.

\section{Resultados e Discussão}

Nos dias antecedentes a visita in loco havia ocorrido eventos de alta precipitação nos limites dos municípios que envolvem a estrada em estudo. As estações automáticas encontradas limítrofes as cidades de Delfinópolis e São João Batista do Glória/MG localizam-se nas cidades de Sacramento/MG (aproximadamente 203 km de distância de Delfinópolis) e Passos/MG (aproximadamente 15,8 km de São João Batista do Glória). Segundo dados de precipitações fornecidos pelo Instituto Nacional de Meteorologia [INMET] (2017), na cidade de Sacramento/MG ocorreram eventos de altas precipitações nos dois dias que antecederam a visita de campo, com quantidade de 58,2 mm e 53,2 mm, respectivamente. Já na cidade de Passos/MG ocorreu a quantidade de $49,4 \mathrm{~mm}$ e $5 \mathrm{~mm}$, respectivamente.

A rodovia não pavimentada em estudo tem a plataforma que apresenta seção transversal de 7,00 (sete) metros de largura no decorrer de sua extensão.

\subsection{Análise geral do meio físico}

Durante o trajeto foram evidenciados trinta e cinco pontos críticos. A inserção desses pontos nos mapas temáticos do Projeto Grande Minas - União Pelas Águas resultou na caracterização do meio físico e da área de abrangência da estrada não pavimentada.

Quanto a declividade, na classe de $<5 \%$ obtiveram-se $51,4 \%$ dos pontos. Na classe 5 a $10 \%$ foram $37,1 \%$ dos pontos encontrados. Na classe 10 a $15 \%$ equivale a $11,5 \%$ dos pontos.

Em relação aos canais de drenagem, verificou-se que há 04 (quatro) canais que interceptam a estrada de estudo e há presença de obras de artes na estrada (pontes). Os cursos hídricos que passam pela estrada de estudo são: Ribeirão Capetinga, Ribeirão Grande, Córrego do Jaú e Córrego da Vargem.

Quanto ao uso e ocupação, nas áreas confrontantes aos pontos críticos verificou-se que há predominância da pastagem (51\%), seguida de área agrícola (37\%) e área de vegetação natural (12\%). 
Quanto a hipsometria, 60\% dos pontos críticos estão localizados na classe de 600 a 700 metros de elevação. Os outros $40 \%$ encontram-se na classe entre 700 a 800 metros de altitude.

\subsection{Análise do solo da camada de revestimento do leito estradal}

No decorrer da estrada foram coletadas sete amostras de solo. A Tabela 1 apresenta os resultados da análise granulométrica conjunta.

Tabela 1 - Classificação do solo do leito estradal.

\begin{tabular}{c|l|c|c|c|c}
\hline \multirow{2}{*}{ Amostras } & \multicolumn{2}{|c|}{$\begin{array}{c}\text { Localização } \\
\text { (coordenadas) }\end{array}$} & \multicolumn{2}{c|}{ Percentual (\%) } & \multirow{2}{*}{ Textura } \\
\cline { 2 - 5 } $\mathbf{1}$ & $\begin{array}{l}\text { Latitude: } 7719236 \mathrm{~m} \mathrm{~N} \\
\text { Longitude: } 341176 \mathrm{~m} \mathrm{E}\end{array}$ & 5 & 10 & 85 & Arenosa \\
\hline $\mathbf{2}$ & $\begin{array}{l}\text { Latitude: } 7719748 \mathrm{~m} \mathrm{~N} \\
\text { Longitude: } 340964 \mathrm{~m} \mathrm{E}\end{array}$ & 47 & 13 & 40 & Argilo-arenosa \\
\hline $\mathbf{3}$ & $\begin{array}{l}\text { Latitude: } 7724431 \mathrm{~m} \mathrm{~N} \\
\text { Longitude: } 340438 \mathrm{~m} \mathrm{E}\end{array}$ & 48 & 12 & 40 & Argilo-arenosa \\
\hline $\mathbf{4}$ & $\begin{array}{l}\text { Latitude: } 7727120 \mathrm{~m} \mathrm{~N} \\
\text { Longitude: } 338555 \mathrm{~m} \mathrm{E}\end{array}$ & 7 & 40 & 53 & Areia-siltosa \\
\hline $\mathbf{5}$ & $\begin{array}{l}\text { Latitude: } 7727714 \mathrm{~m} \mathrm{~N} \\
\text { Longitude: } 333578 \mathrm{~m} \mathrm{E}\end{array}$ & 30 & 30 & 40 & Areia silto-argilosa \\
\hline $\mathbf{6}$ & $\begin{array}{l}\text { Latitude: } 7730704 \mathrm{~m} \mathrm{~N} \\
\text { Longitude: } 330732 \mathrm{~m} \mathrm{E}\end{array}$ & 18 & 50 & 32 & Silte-arenosa \\
\hline $\mathbf{7}$ & $\begin{array}{l}\text { Latitude: } 7731689 \mathrm{~m} \mathrm{~N} \\
\text { Longitude: } 329721 \mathrm{~m} \mathrm{E}\end{array}$ & 15 & 43 & 42 & Silte-arenosa \\
\hline
\end{tabular}

Fonte: Autores (2021).

Os resultados encontrados nas análises laboratoriais dos solos apresentaram a seguinte caracterização: um ponto na classificação de textura Arenosa; dois pontos classificados como de textura argilo-arenosa; um ponto classificado como textura areia-siltosa; um ponto areia silto-argilosa e dois pontos classificados como de textura silte-arenosa.

Devido a variação da textura dos solos nos pontos de amostragem pode-se constatar que os materiais de revestimento do leito estradal são de áreas de empréstimos.

\subsection{Análise dos pontos críticos}

Foram elencados cincos para descrição que apresentaram semelhança nas características do meio físico e dos problemas encontrados com os outros trinta pontos.

\subsubsection{Ponto 1}

O Ponto 1 (P1) está localizado nas coordenadas 341789mE e 7718570mN. As características do meio físico são: A geologia da área é $\mathrm{AR}(\mathrm{X} 1)$, que representa mica-xisto com intercalação de quartzo-xisto, quartzito, anfibolito e gnaisse; a hipsometria varia na classe de 700 a 800 metros e a declividade na classe de 5 a 10\%. O P1 está inserido em área de pastagem. É o início da estrada de estudo, no sentido São João Batista do Glória ao Distrito de Delfinópolis denominado Ponte Alta. Há placas de sinalização localizando as pousadas, cachoeiras, loteamento e também a direção do Distrito Ponte Alta. Na lateral da estrada há o acúmulo de grande quantidade de material de revestimento do leito estradal, evidenciando a passagem de motoniveladora para reconformação da pista (Figura 2). Essa forma de manutenção, se não operada adequadamente, ocasiona o 
acúmulo de material nas sarjetas, desfavorecendo o abaulamento transversal, dificultando o funcionamento do sistema de drenagem da estrada.

Figura 2 - Registro fotográfico do Ponto 1.

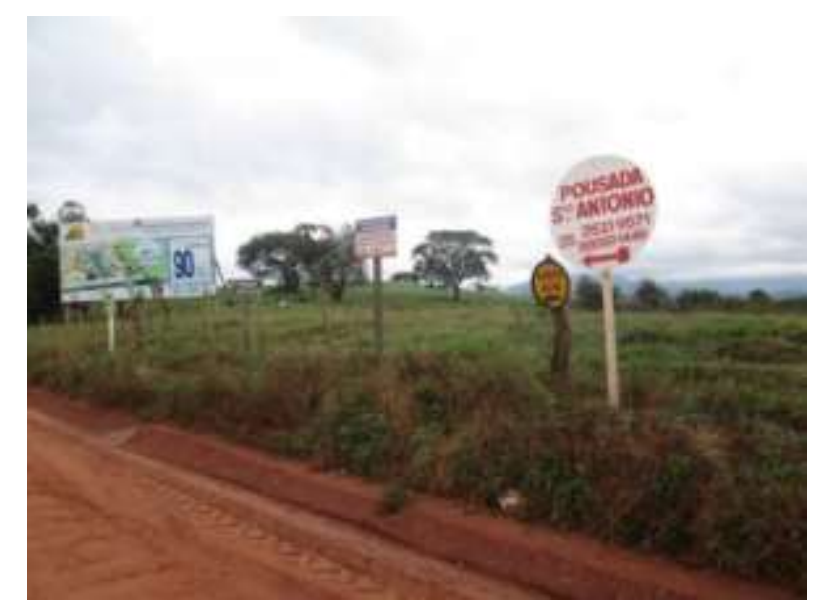

Fonte: Autores (2021).

\subsubsection{Ponto 2}

O Ponto 2 (P2) se localiza nas coordenadas 341176mE e 7719236mN. As características do meio físico são: A Geologia do ponto é AR (X1), a hipsometria varia na classe de 700 a 800 metros e a declividade na classe de $<5 \%$. O ponto P2 está inserido em uma área agrícola.

Há duas bacias de contenção que se encontraram ativas, pois havia grande quantidade de água pluvial acumulada, devido aos eventos de precipitação ocorridos antecedentes a visitação in loco. As bacias necessitam de manutenção periódica como a roçagem das gramíneas das bordas laterais do bigode (Figura 3).

Constatou-se acúmulo de resíduos sólidos na lateral do bigode, impactando o sistema de drenagem pluvial e a paisagem da estrada. Na lateral esquerda da pista há caçambas para o despejo de resíduos sólidos dos rancheiros e roceiros que habitam nas imediações da estrada. É necessária a conscientização da população rural do entrono para a disposição dos resíduos em locais apropriados, como também, políticas públicas que contemplem essa temática.

A medida de controle ambiental apresentada como parte de programas municipais de gestão ambiental, contribuem para a preservação do meio ambiente, conservação e limpeza da estrada, possibilitando o surgimento de uma cultura de comportamento favorável ao ambiente. 
Figura 3 - Registro fotográfico do Ponto 2.
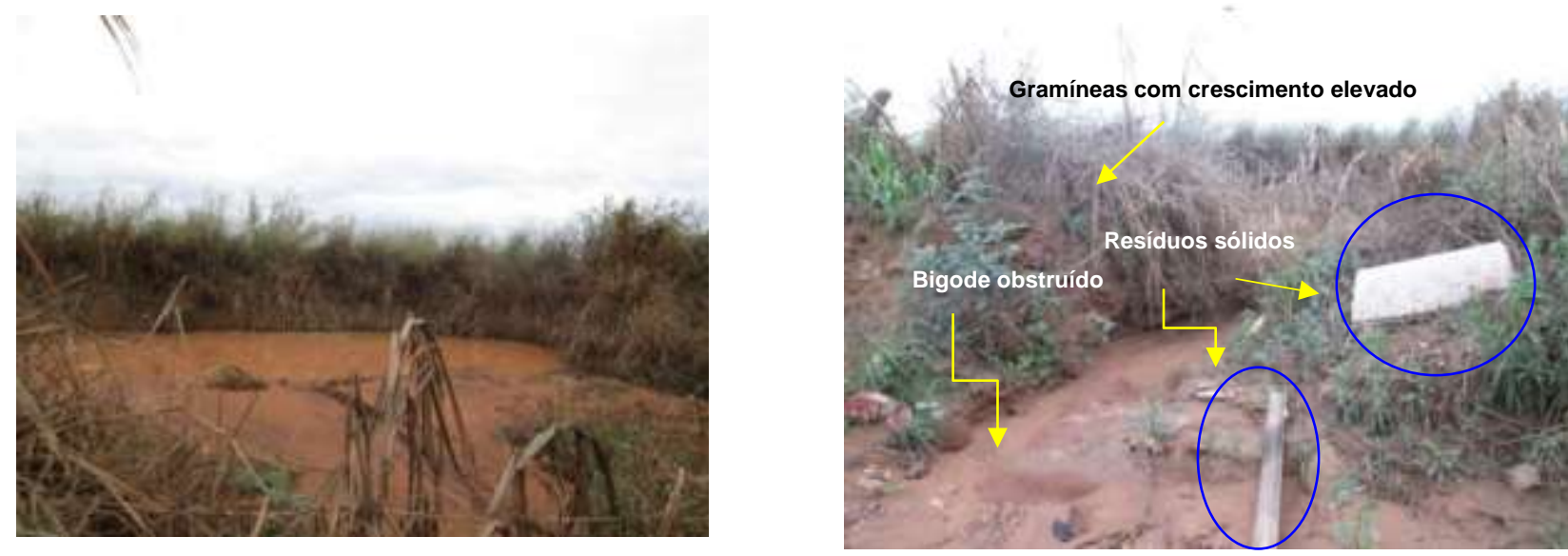

Fonte: Autores (2021).

\subsubsection{Ponto 3}

O Ponto 3 (P3) está localizado nas coordenadas 340476 mE e 7720860 mN. As características do meio físico são: A Geologia da área é AR (X1), a hipsometria varia na classe de 600 a 700 metros e a declividade na classe de $<5 \%$. O P3 está inserido em área de vegetação natural.

Nesse trecho há uma obra de arte (ponte) sobre o Ribeirão Capetinga. Como forma de segurança de tráfego e dos usuários, a ponte se apresenta com dispositivos de guarda corpo em concreto, porém necessita de placas de sinalização de trânsito no local, alertando a presença da ponte no trecho. Há acúmulo de água pluvial na lateral e corrugações transversais, o que evidencia uma deficiência nos dispositivos de drenagem pluvial (sarjeta) (Figura 4).

Como forma de manutenção, recomenda-se nesse trecho execução do abaulamento transversal da pista, através máquinas de motoniveladora e/ou patrol para a reconformação da pista de rolamento e reestabelecimento do sistema de drenagem superficial.

Por esse ponto estar próximo de um curso hídrico, o sistema de drenagem pluvial deve ser restabelecido o mais rápido possível, evitando assim o assoreamento do mesmo.

Figura 4 - Registro fotográfico do Ponto 3.
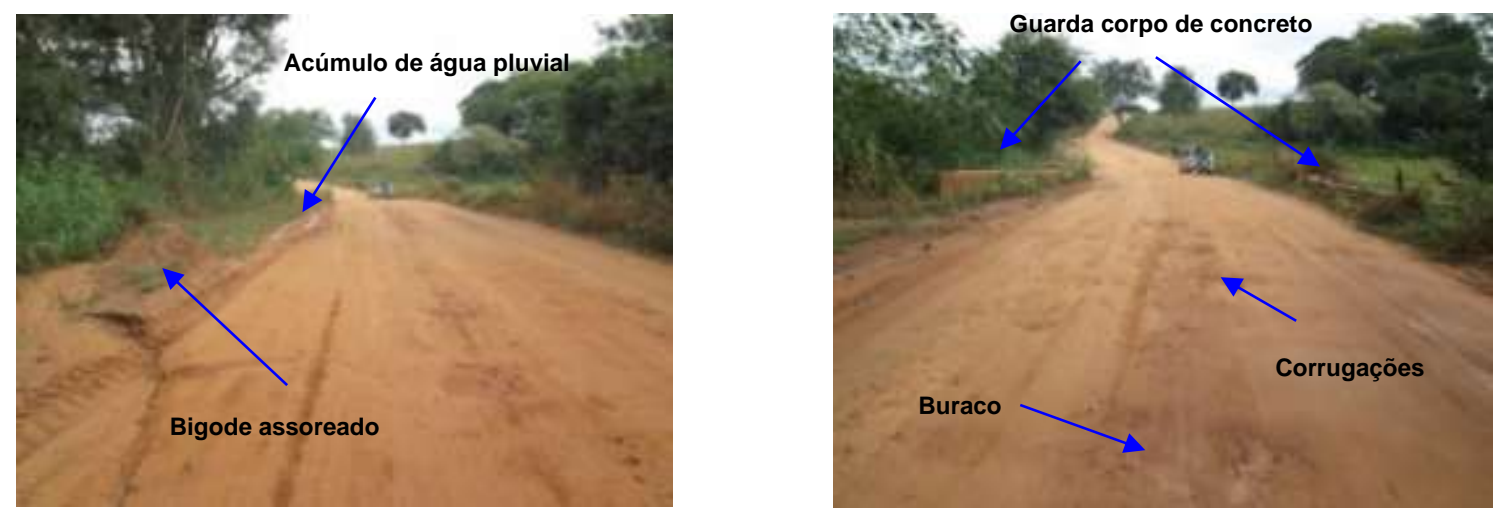

Fonte: Autores (2021). 


\subsubsection{Ponto 4}

O Ponto 4 (P4) está localizado nas coordenadas 340433 mE e 7721424 mN. As características do meio físico são: A Geologia é AR (X1), a hipsometria varia na classe de 600 a 700 metros e a declividade na classe de $<5 \%$. O P4 está inserido em área de vegetação natural.

O P4 encontra-se localizado entre duas altas declividades. Corresponde ao trecho que possui uma obra de arte (ponte) sobre o Ribeirão Capetinga (Figura 5). O trecho possui sinalização de trânsito que alerta aos usuários que há uma ponte no local, porém a ponte não tem proteção lateral de guarda-corpo.

Há necessidade de implementar medida de prevenção de riscos de acidentes nesse trecho, como a construção de guarda corpo e sinalizações de trânsito, para prezar a segurança dos usuários.

Há também nesse trecho placas informativas das pousadas e cachoeiras da região com suas respectivas quilometragens de distância do ponto. Essa medida é de extrema importância em regiões turísticas, considerando que grande parte dos turistas não conhece a região, assim, essas placas ajudam a se localizarem.

Houve a constatação de deposição de resíduos sólidos na pista de rolamento. A conscientização com placas de "não jogar lixo nas vias" faz-se necessário.

No trecho há formação de caminhos preferenciais da água pluvial e corrugações, o que evidencia um abaulamento transversal com declividade inadequada e dispositivo de direcionamento de água pluvial (bigode) obstruídos, onde as águas pluviais são direcionadas para o talvegue natural.

Recomenda-se como medida de manutenção, com uso de máquinas patrol e/ou motoniveladora para reconformação da pista, limpeza dos bigodes, e roçagem das gramíneas para a eficiência do sistema de drenagem pluvial nesse trecho.

Figura 5 - Registro fotográfico do Ponto 4.
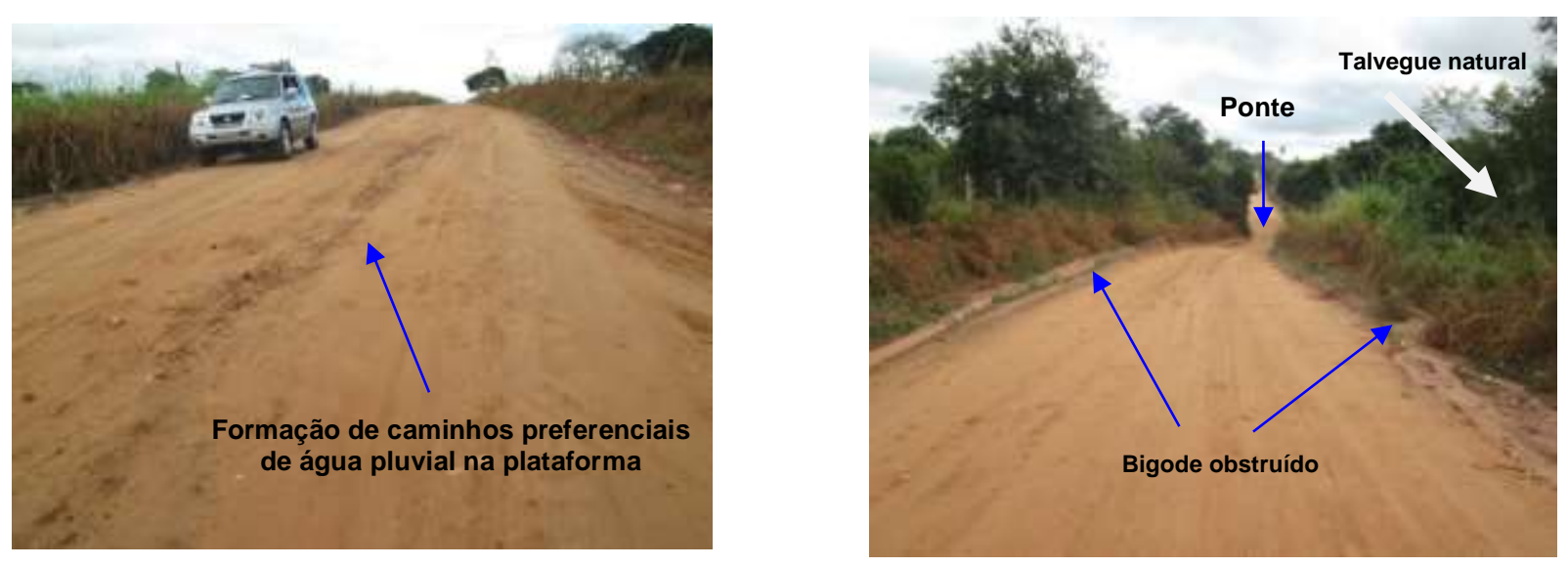

Fonte: Autores (2021).

\subsubsection{Ponto 5}

O Ponto 5 (P5) está localizado nas coordenadas 337745 mE e 7727145 mN. As características do meio físico são: A geologia da área é AR(X2), que representa mica-xisto com intercalações comuns de quartzito; a hipsometria é 600 a 700 metros e a declividade está na classe de 5 a 10\%. O P5 está inserido em área de vegetação natural na lateral direita e área agrícola na lateral esquerda.

Nesse trecho inicia-se um processo de formação de corrugações, com severidade alta, evoluindo para erosão do tipo sulcos (Figura 6). A origem desse problema possivelmente foi do adiamento de uma intervenção de manutenção no defeito, ocasionado pela evasão da fração fina. Para solução desse defeito Baesso e Gonçalves (2003, p.83) recomendam "um material 
de revestimento apresentando composição adequadamente balanceada, contando com a presença de fração plástica que lhe confere poder de aglutinação à mistura", ou seja, argilas possuem essa importante propriedade. Logo após a mistura ser inserida na camada de revestimento, recomenda a passagem de rolo compactador e/ou motoniveladora (em caso de não haver rolo compactador).

Pode-se observar visualmente ser um trecho com alta suscetibilidade à erosão, por apresentar início ao processo erosivo junto às áreas marginais. A aplicação de gramíneas locais após recuperação preliminar das erosões que se formaram contribuirá para estabilizar estas áreas.

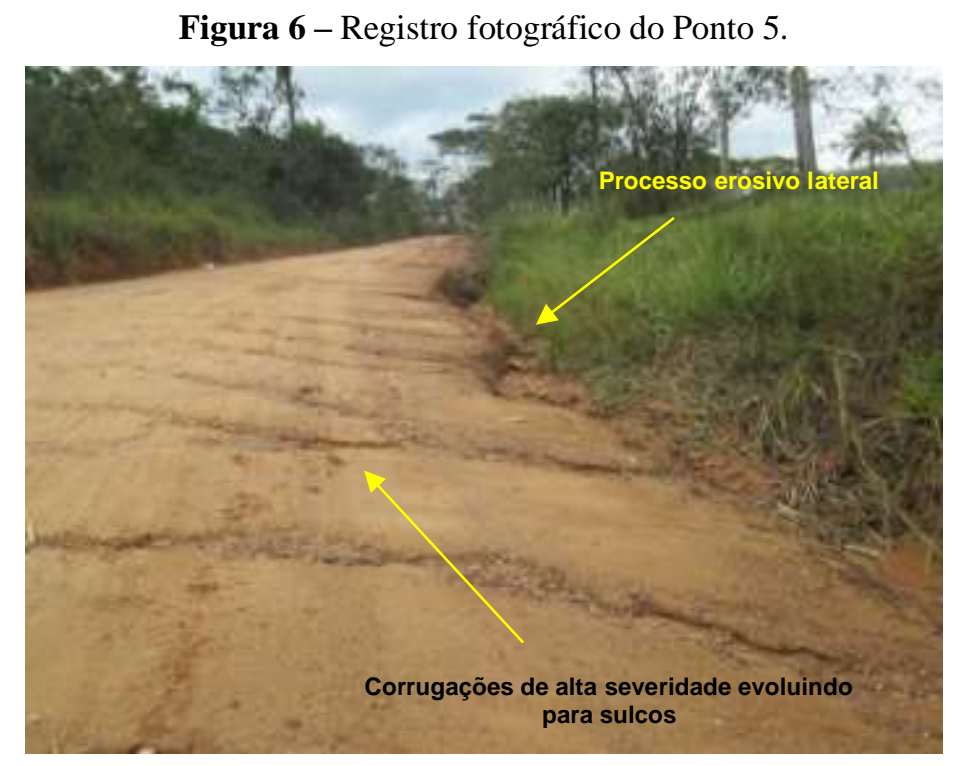

Fonte: Autores (2021).

O Quadro 1 sintetiza as informações obtidas, para uma visão geral das degradações, impactos ambientais e problemas instalados analisadas de acordo com seu meio físico, biótico ou antrópico de cada ponto selecionado. 
Quadro 1 - Análise dos meios físico, biótico e socioeconômico dos pontos.

\begin{tabular}{|c|c|}
\hline \multicolumn{2}{|r|}{ Meio Físico } \\
\hline \multirow{2}{*}{$\begin{array}{l}\text { - Erosão } \\
\text {-Inoperância dos sistemas de } \\
\text { drenagem pluvial; }\end{array}$} & Problemas encontrados \\
\hline & $\begin{array}{l}\text { P5: Processo erosivo na sarjeta lateral da pista; Corrugações em alto } \\
\text { nível de severidade evoluindo para sulcos. }\end{array}$ \\
\hline \multicolumn{2}{|r|}{ Meio Biótico } \\
\hline \multirow[b]{2}{*}{$\begin{array}{l}\text { - Assoreamento de curso hídrico; } \\
\text { - Poluição do solo e água; } \\
\text { - Presença de resíduos sólidos; } \\
\text { - Assoreamentos de talvegues, } \\
\text { retenção do fluxo de águas } \\
\text { superficiais; }\end{array}$} & Problemas encontrados \\
\hline & $\begin{array}{l}\text { P1: Material do revestimento primário (agregados) assoreando as } \\
\text { sarjetas, podendo carrear para cursos hídricos em eventos } \\
\text { pluviométricos. } \\
\text { P2: Resíduos sólidos lançados nos dispositivos de drenagem, causando } \\
\text { poluição do solo e água. } \\
\text { P4: Deposição de resíduos sólidos podendo causar contaminação do solo } \\
\text { e da água; Bigode assoreado direcionando água pluvial para o talvegue } \\
\text { natural. }\end{array}$ \\
\hline \multicolumn{2}{|r|}{ Meio Socioeconômico } \\
\hline \multirow[b]{2}{*}{$\begin{array}{l}\text { - Baixa qualidade de vida e } \\
\text { desconforto aos usuários; } \\
\text { - Acidentes de trânsitos } \\
\text { envolvendo os usuários; } \\
\text { - Danos aos veículos pela má } \\
\text { conservação da pista; }\end{array}$} & Problemas encontrados \\
\hline & $\begin{array}{l}\text { P3: Acúmulo de água pluvial corrugações e buracos na plataforma, } \\
\text { causando danos aos usuários e encurtamento da pista para tráfego, } \\
\text { podendo ocasionar acidentes; sem sinalização de trânsito alertando da } \\
\text { ponte, afetando a segurança dos usuários; } \\
\text { P4: Ausência de dispositivos de segurança na lateral da ponte (guarda } \\
\text { corpo) e placas de sinalização de trânsito podendo causar acidentes entre } \\
\text { os usuários; Corrugações causando desconforto aos usuários e danos aos } \\
\text { veículos; } \\
\text { P5: Corrugações com alto nível de severidade, causando desconforto aos } \\
\text { usuários e danos aos automóveis. }\end{array}$ \\
\hline
\end{tabular}

Fonte: Autores (2021).

O Quadro 2 apresenta a descrição detalhada dos tipos de degradação encontrados em cada um dos pontos críticos analisados na estrada.

Quadro 2 - Descrição das características dos problemas encontrados.

\begin{tabular}{|c|c|c|}
\hline Pontos & Descrição do problema & Observações \\
\hline $\mathrm{P} 1$ & $\begin{array}{l}\text { Comprometimento do sistema de } \\
\text { drenagem pluvial do trecho (sarjeta e } \\
\text { abaulamento transversal). } \\
\text { - Agregados da camada de revestimento } \\
\text { soltos }\end{array}$ & $\begin{array}{l}\text { Há indícios de operação incorreta da passagem de } \\
\text { motoniveladora, pelo fato do acúmulo de } \\
\text { agregados da camada de revestimento nas } \\
\text { sarjetas. }\end{array}$ \\
\hline $\mathrm{P} 2$ & $\begin{array}{l}\text {-Resíduos sólidos nos dispositivos de } \\
\text { drenagem. } \\
\text {-Ausência de limpeza e manutenção dos } \\
\text { dispositivos de drenagem. }\end{array}$ & $\begin{array}{l}\text { As degradações poderão ocorrer devido à falta de } \\
\text { manutenção das duas bacias de contenção, cuja } \\
\text { profundidade é } \cong 0,5 \mathrm{~m} \text { e } 0,7 \mathrm{~m} \text { respectivamente. }\end{array}$ \\
\hline P3 & $\begin{array}{l}\text {-Acumulo de água pluvial na lateral; } \\
\text {-Corrugações de baixa severidade } \\
\text {-Buracos na pista. }\end{array}$ & $\begin{array}{l}\text { Ponte sobre o Ribeirão Capetinga. Dispositivo de } \\
\text { drenagem pluvial assoreado. }\end{array}$ \\
\hline P4 & $\begin{array}{l}\text {-Resíduos sólidos na via; } \\
\text {-Presença de corrugações; } \\
\text {-Formação de caminhos preferenciais de } \\
\text { água pluvial na pista. }\end{array}$ & Ponte sobre o Ribeirão Capetinga. \\
\hline P5 & $\begin{array}{l}\text {-Corrugações em níveis de alta } \\
\text { severidade; } \\
\text {-Desencadeamento de processos erosivos } \\
\text { nas marginas do trecho; }\end{array}$ & $\begin{array}{l}\text { Corrugações em alta severidade, evoluindo para } \\
\text { sulcos. Processo erosivo na lateral devido ao solo } \\
\text { com alta suscetibilidade a erosão. }\end{array}$ \\
\hline
\end{tabular}

Fonte: Autores (2021). 
O Quadro 3 refere-se à descrição da avaliação das medidas de controle existentes e que deverão ser implantadas nos pontos críticos analisados.

Quadro 3 - Identificadas das medidas a serem implementadas para conservação da via.

\begin{tabular}{|c|c|c|}
\hline Pontos & Localização (coordenadas) & Medidas para implementar \\
\hline P1 & $\begin{array}{l}\text { Longitude (X): } 341789 \mathrm{~m} \\
\text { Latitude (Y): } 7718570 \mathrm{~m}\end{array}$ & $\begin{array}{l}\text { - Cursos para os operários de capacitação em manutenção de } \\
\text { estradas não pavimentadas com máquinas motoniveladora. } \\
\text { - Reconformação da pista através da reintrodução dos } \\
\text { agregados soltos na camada de revestimento }\end{array}$ \\
\hline $\mathrm{P} 2$ & $\begin{array}{l}\text { Longitude (X): } 341176 \mathrm{~m} \\
\text { Latitude (Y): } 7719236 \mathrm{~m}\end{array}$ & $\begin{array}{l}\text { - Manutenção periódica dos dispositivos de drenagem pluvial. } \\
\text { - Conscientização dos usuários quanto a acumulação dos } \\
\text { resíduos em locais apropriados. }\end{array}$ \\
\hline P3 & $\begin{array}{l}\text { Longitude (X): } 340476 \mathrm{~m} \\
\text { Latitude (Y): } 7720860 \mathrm{~m}\end{array}$ & $\begin{array}{l}\text { - Manutenção das sarjetas. } \\
\text { - Construção de dispositivos de saídas de água pluvial } \\
\text { (bigode). } \\
\text { - Reconstrução do abaulamento transversal do trecho. } \\
\text {-Sinalização de trânsito alertando da ponte. }\end{array}$ \\
\hline P4 & $\begin{array}{l}\text { Longitude (X): } 340433 \mathrm{~m} \\
\text { Latitude (Y): } 7721424 \mathrm{~m}\end{array}$ & $\begin{array}{l}\text { - Sinalização de trânsito para segurança dos usuários; } \\
\text { - Proteção da ponte com guarda corpo; } \\
\text { - Manutenção dos dispositivos de drenagem pluvial; } \\
\text { - Alocação de placas com a seguinte mensagem "proibido } \\
\text { jogar lixo na via". } \\
\text { - Reconstrução do abaulamento transversal da pista; }\end{array}$ \\
\hline P5 & $\begin{array}{l}\text { Longitude (X): } 337745 \mathrm{~m} \\
\text { Latitude (Y): } 7727145 \mathrm{~m}\end{array}$ & $\begin{array}{l}\text { - Introdução de agregados no material de revestimento que } \\
\text { deverá apresentar composição adequadamente balanceada, } \\
\text { contando com a presença de fração plástica (argila) que lhe } \\
\text { confere poder de aglutinação à mistura. A mistura a ser } \\
\text { inserida na camada de revestimento, recomenda-a passagem } \\
\text { de rolo compactador e/ou motoniveladora; } \\
\text { - Aplicação de gramíneas locais após preliminar recuperação } \\
\text { das erosões que se formaram certamente estabilizará a erosão } \\
\text { no trecho. }\end{array}$ \\
\hline
\end{tabular}

Fonte: Autores (2021).

\section{Considerações Finais}

Os resultados dessa pesquisa são importantes para auxiliar a gestão administrativa dos munícipios de São João Batista do Glória-MG e Delfinópolis-MG na adoção de práticas conservacionistas aplicáveis a manutenção e conservação das estradas não pavimentadas, com vistas ao aprimoramento das técnicas de manutenção referente a trafegabilidade e ao gerenciamento ambiental.

Para a mitigação de aspectos e impactos ambientais negativos, advindos de estradas não pavimentadas, o conhecimento relativo ao gerenciamento planejado, sem improvisos, e de atributos influentes nessas intervenções são fundamentais, pois auxilia a gestão financeira e de trafegabilidade. Acrescenta-se a essa percepção, a importância de uma visão mais abrangente, envolvendo as contribuições do meio físico, para a gestão de recursos hídricos e solos, uma vez que, a erosão (e suas consequências) é o fator resultante que mais se evidencia em estradas de terra.

Com relação aos mapas do meio físico, estes tiveram a prerrogativa de transmitir informações rápidas e de fácil compreensão, registrando dados pertinentes para avaliação dos "pontos críticos" e entornos influentes. Além disso, ressalta-se que a visita in loco foi de suma importância para aferição de detalhes, levantamentos dos defeitos relativos à trafegabilidade e avaliação das medidas de controle existentes.

Recomenda-se para realização de trabalhos futuros, que a pesquisa se estenda a outras estradas não pavimentadas na 
abrangência do Médio Rio Grande (CBH-GD7), numa ação de aplicabilidade do Projeto Grande Minas, que trata do Zoneamento Ambiental dessa área, pois além de auxiliar na gestão pública, também a gestão dos recursos hídricos será efetivamente contemplada.

\section{Referências}

Almeida, C. N. R. de. (2014). Estudo Geoambiental da Região da Serra da Canastra - MG: Potencialidades e Restrições ao Uso Turístico. Dissertação, Universidade do Estado de São Paulo, São Carlos, São Paulo, Brasil.

Andrade, C. O. P., Carvalho, R. C. R., Godinho, R. F., \& Magri, R. A. F. (2016). Elaboração e aplicação de uma rota de trekking em uma área do Parque Nacional da Serra da Canastra. Revista Brasileira de Ecoturismo, 9(2), 285-317.

Associação Brasileira de Normas Técnicas. (2016). NBR 7181: Solo: Análise Granulométrica. Versão corrigida 2:2018.

Baesso, D. P., \& Gonçalves, F. L. R. (2003). Estradas rurais técnicas adequadas de manutenção: DER.

Bertolini, D., Drugowich, M. I., Lombardi Neto, F., \& Bellinazzi Junior, R. (1994). Controle de Erosão em Estradas Rurais. In: Bertolini, D., Kroll, F. M., Lombardi Neto, F., Crestana, M. S. M., Drugowich, M. I., Elias, R., Corrêa, R. O., \& Bellinazzi Junior, R. (1994). Manual Técnico de Manejo e Conservação do Solo e Água: Tecnologias disponíveis para a implementação de técnicas complementares no solo (pp. 1-23).: CATI.

Confederação Nacional De Transportes. (2020). Boletim Estatístico de Fevereiro. https://www.cnt.org.br/boletins

Casarin, R. D. (2008). Controle de erosão em estradas não pavimentadas, utilizando sistema de terraceamento com gradiente associado à bacia de captação. Dissertação, Universidade Estadual Paulista, Botucatu, São Paulo, Brasil.

Casarin, R. D., \& Oliveira, E. L. (2009). Controle de Erosão em estradas rurais não pavimentadas, utilizando sistema de terraceamento com gradiente associado a bacias de captação. Irriga, 14(4), 548-563.

Biazotti Collares, A. C. Z., Gomes, D. M., Silva, J. A., Pereira, S. A., \& Collares, E. G. (2013). Aspectos Metodológicos: Hidrografia e caracterização morfométrica. In: Collares, E. G. (2013) Zoneamento Ambiental das Sub-Bacias Hidrográficas dos Afluentes Mineiro do Médio Rio Grande (pp. 153-162). Passos, MG: Edifesp.

Collares, E. G., \& Gomes, D. M. (2013). Aspectos dos Meios Físico e Biótico: Geologia. In: Collares, E. G. (2013) Zoneamento Ambiental das Sub-Bacias Hidrográficas dos Afluentes Mineiro do Médio Rio Grande (pp. 154-164). Passos, MG: Edifesp.

Collares, E. G., Gomes, D. M., \& Santos, B. M. dos. (2013). Aspectos Metodológicos: Compartimentação em macrounidades e unidades ambientais. In: Collares, E. G. (2013) Zoneamento Ambiental das Sub-Bacias Hidrográficas dos Afluentes Mineiro do Médio Rio Grande (pp. 49-62): Edifesp.

Cunha, M. C., Thomaz, E. L., \& Vestena, L. R. (2012). Medidas de controle de erosão em estradas rurais na Bacia do Rio Das Pedras. Sociedade \& Natureza, 1(25), 107-118.

Cunha, M. C., Santos, R. V., \& Cruz, A. A. (2014). Levantamento das medidas de manutenção aplicado nas estradas rurais na bacia do Rio das Pedras. Caderno de Geografia, 24(42), 124-138.

Dias, C. C., Vilela, F. R., Santos, B. M. dos., Collares, E. G., \& Pejon, O. J. (2013). Aspectos Socioeconômicos e de Uso e Ocupação do Solo: Diagnóstico do Uso e Ocupação do Solo. In: Collares, E. G. (2013) Zoneamento Ambiental das Sub-Bacias Hidrográficas dos Afluentes Mineiro do Médio Rio Grande (pp. 138153): Edifesp.

Fonseca, C. E. (2012). O município de Delfinópolis, MG, e o desenvolvimento do setor turístico no espaço geográfico. Caminhos de Geografia, 13(42), 59-74.

Godinho, R. F., Soares, V. E., Bertipaglia, L. M. A., Carvalho, R. C. R., \& Dian, P. H. M. (2012). Caracterização da produção leiteira em São João Batista do Glória (MG). Ciências Et Praxis, 6(10), 15-20.

Instituto Brasileiro de Geografia e Estatística. (2010). Panorama geral de Delfinópolis. https://cidades.ibge.gov.br/brasil/mg/delfinopolis/panorama

Instituto Brasileiro de Geografia e Estatística. (2010). Panorama geral de São João Batista do Glória. https://cidades.ibge.gov.br/brasil/mg/sao-joao-batista-dogloria/panorama

Instituto Brasileiro de Geografia e Estatística. (2010). Sinopse do Censo Demográfico de 2010. https://censo2010.ibge.gov.br/sinopse/i ndex.php?dados $=29 \& u f=31$

Instituto Brasileiro do Meio Ambiente e dos Recursos Naturais Renováveis. (2005). Plano de Manejo do Parque Nacional da Serra da Canastra. Ministério do Meio Ambiente: Brasília-DF.

Instituto Nacional de Meteorologia (2017). Banco de dados meteorológicos. http://www.inmet.gov.br/portal/index.php?r=estacoes/estacoesAutomaticas >

Martins, A. S., Campos, D. B. da C., \& Nascimento, M. das V. do. (2019). Estradas vicinais não pavimentadas: avaliação das condições de trafegabilidade em trecho contido em comunidade do Sertão de Pernambuco, Brasil. Research, Society and Development, 9(10), 1-24. 10.33448/rsd-v9i10.8652

Magri, R. A. F., Pejon, O. J., \& Collares, E. G. (2013). Aspectos dos Meios Físico e Biótico: Caracterização do relevo. In: Collares, E. G. (2013) Zoneamento Ambiental das Sub-Bacias Hidrográficas dos Afluentes Mineiro do Médio Rio Grande (pp. 118-153): Edifesp. 
Research, Society and Development, v. 10, n. 3, e22110313236, 2021

(CC BY 4.0) | ISSN 2525-3409 | DOI: http://dx.doi.org/10.33448/rsd-v10i3.13236

Mortoni, D. M. C., Gonçalves, S. L. S., \& Nascimento, R. C. B. do. (2020). Análise da influência de estradas não pavimentadas na concentração de metais pesados em áreas agrícolas. Braz. J. of Develop., 6(5), 23208-23218.

Santos, B. M., Oliveira, B. M. dos., Biazotti Collares, A. C. Z. B., Pereira, T. C. F. K., \& Collares, E. G. Aspectos Socioeconômicos e de Uso e Ocupação do Solo: Diagnóstico do Sistema Viário. In: Collares, E. G. (2013) Zoneamento Ambiental das Sub-Bacias Hidrográficas dos Afluentes Mineiro do Médio Rio Grande (pp. 88-137). Passos, MG: Edifesp.

Pereira, A.S., Shitsuka, D. M., Parreira, F. J., \& Shitsuka, R. (2018). Metodologia da Pesquisa Científica. UFSM. 